\title{
Molecular Characterization and Pathogenesis of the Baculovirus Anprnpv Causing Tiger Band Disease in Antheraea Proylei (Oak Tasar Silkworm)
}

\section{Diksha Khajje}

Seribiotech Research Laboratory

\section{Sinam Subharani Devi}

Seribiotech Research Laboratory

\section{Anupama Jagadish}

Seribiotech Research Laboratory

Himanshu Dubey

Seribiotech Research Laboratory

Vankadara Sivaprasad

Seribiotech Research Laboratory

Olle Terenius

Uppsala University: Uppsala Universitet

Ponnuvel Kangayam Muthusamy ( $\sim$ kmpvel@gmail.com )

Seribiotech Research Laboratory https://orcid.org/0000-0002-2475-9180

\section{Research Article}

Keywords: viral disease, oak silkworm, vertical transmission, egg surface, disinfection

Posted Date: August 26th, 2021

DOI: https://doi.org/10.21203/rs.3.rs-823037/v1

License: (c) (1) This work is licensed under a Creative Commons Attribution 4.0 International License. Read Full License 


\section{Abstract}

The temperate oak tasar silkworm Antheraea proylei is frequently infested by tiger band disease caused by Antheraea proylei nucleopolyhedro virus (AnpINPV). The disease is characterised by dark tiger-like strips across the body of the silkworm, causing an increased mortality and poor seed cocoon recovery. The study confirms that the spread of the disease is particularly high in autumn seasons pertaining to high temperature and humidity conditions. The virus displays a higher copy number in the fatbody tissue and is also able to spread and multiply in various development stages such as egg, larvae, pupa and moth of infected $A$. proylei silkworms. To check the cross-infectivity of the virus on the silkworm species Antheraea pernyi, A. frithi and Samiaricini and some other lepidopteran species (Phalera raya, Hablaea peura, Pieris canidiaand $P$. brassicae), virus inoculum was introduced into early-stage larvae. All the silkworm species died acquiring the infection, whereas inoculation into other lepidopteran pests did not have any impact on their survival, indicating the host range of this virus was limited to the silkworm clade. The virus follows a transovum vertical transmission route where hatched larvae laid by infected mother moths were found to contain virus. The surface of eggs is identified to be the potential source of infection since poorly washed eggs displayed the presence of virus on the outer surface whereas was absent in the inner contents of the surface-washed eggs. Hence, a surface disinfection method with $0.2 \%$ sodium hypochlorite has been devised from this study that can prevent the occurrence and spread of this virus. Similarly, a PCR as well as an qRT-PCR method has been developed for detection of the virus during early stages of infection in A. proylei silkworms.

\section{Introduction}

Temperate or oak tasar is one of the types of wild silk extracted from the oak tasar silkworm Antheraea proylei [12]. The members found under the genus Antheraea occupy different ecological niches, ranging from tropical to temperate with transitional zones. Among the several species of oak tasar silkworms, Antheraea roylei, A. frithi, etc., which feed on food plant Quercus, A. proylei Jolly is the most prominent, viable and commercially exploited species in India [2]. The oak tasar cultivation is followed throughout the sub-Himalayan belt extending from Jammu and Kashmir in the north to Manipur in the far East [18]. The oak flora plays a significant role in enhancing the economy of the hill tribes as well as the economically backward communities residing in the foothills of Himalayas. It plays an important role as it provides an alternate source of income to enhance the livelihood of small-scale farmers and several tribal communities [2]. Oak tasar and tasar silk alone accounts for nearly $90 \%$ of the global non-mulberry silk production [6]. Almost 7.3 tons of raw oak tasar silk was produced in 2019 in Manipur alone [4].

A. proylei (the oak tasar silkworm)is an interspecific hybrid of $A$. roylei of India and A. pernyi of China [19].Oak tasar silkworms are prone to many diseases such as microsporidiosis, virosis, bacteriosis and mycosis, since they are nondomesticated and feeds on trees in the wild. Tigerband disease is one of the most common and the most dreadful disease infecting the oak tasar silkworms causing severe losses to sericulture industry with variations in temperature and humidity being the main contributing factors for the disease in $A$. proylei larvae [13]. The damage caused by the virus is responsible for almost $70-80 \%$ of larval and pupal mortality [4]. Larvae infected with AnpNPV shows poor growth and development along with loss of appetite and appearance of black bands on the worm's segments (hence, the name tiger band disease) [1]. Other symptoms include shrinkage and softening of body finally leading to death. The disease shows horizontal as well as vertical transmission, also there are studies indicating heavy gonadal infection confirming a vertical mode of transmission [3]. The predisposing factors for the disease occurrence include high humidity associated with high temperature [3].

Shantibala et al. (2018) have identified and characterized the casual organism of tiger band disease to be A.proylei nucleopolyhedrovirus (AnprNPV), which belongs to group 1 alpha baculoviruses. Genetically, these baculoviruses have a double stranded supercoiled circular DNA genome with a molecular size ranging from 80 to 180kb [18]. These viruses cause arthropod-specific viral diseases in more than 600 insect species, with most examples occurring in the order Lepidoptera, and some in the orders Hymenoptera and Diptera [17]. Furthermore, AnprNPV and A. pernyi nucleopolyhedrovirus (AnpeNPV) isolates have a nucleotide sequence identity of about $98 \%$, which strongly suggests that AnprNPV is a local variant of AnpeNPV [18]. 
The current study was designed to explore the various unknown aspects regarding the causative virus and to understand the etiology of the tiger band disease infecting the oak tasar silkworm A. proylei. More studies and increased knowledge on the disease will further help us understand the host-pathogen relationship in addition to designing better disease control strategies leading to improved crop yields and better sericulture economy in the North East and North West regions of India.

\section{Materials And Methods}

\section{Survey and collection of disease-infected oak tasar silkworms}

The survey and collection of disease-infected A. proylei larvae/silkworms were performed in different sericulture farms during spring (February to April) and autumn (October to November) seasons in Manipur and Nagaland in the year 20172018. Larval mortality was the end point for the analysis in both seasons for the survey. The data also took into account the correlation of meteorological relevance to the larval mortality in different areas. The correction analysis was also performed for different districts in Manipur and at spring and autumn season for abiotic factors such as temperature and humidity at a significance value of $5 \%$.

\section{Electron microscopy}

Transmission electron microscopy (TEM) was used to examine the polyhedrin matrix within OBs. For this, OBs were pelleted by centrifugation at $5000 \mathrm{~g}$ for $5 \mathrm{~min}$. OBs in suspension were fixed for overnight at room temperature with $3 \%$

glutaraldehyde. The samples were then concentrated in $1 \mathrm{ml}$ of cacodylate buffer and they were post-fixed with $2 \%$ osmium tetroxide $\left(\mathrm{OsO}_{4}\right)$ for $2 \mathrm{~h}$ at $4 \llbracket \mathrm{C}$. Samples were dehydrated using ethanol and stained for $1 \mathrm{~h}$ with $2 \%$ uranyl acetate. The samples were then subjected to propylene oxide to remove residual ethanol previously used for dehydration.

The samples were embedded in araldite resin and polymerized for $48 \mathrm{~h}$ at $60 \otimes \mathrm{C}$. After polymerization, samples were sectioned using an ultra-microtome, transferred to TEM grids and stained with lead acetate. The resulting grids were observed under an electron transmission microscope of $100 \mathrm{kV}$ (JEOL JEM 1400 plus). Different fields of each sample were photographed at a magnification of 40,000 and visualized with image acquisition software.

\section{Isolation of viral polyhedra}

Putrefied A. proylei larvae cadavers were filtered through cheese cloth and subjected to centrifugation at $100 \mathrm{~g}$ for 2 mins to remove the floating debris. The supernatant was collected and further centrifuged at $4000 \mathrm{~g}$ for 15 mins to pellet the polyhedra. The pellet was washed thrice at room temperature with $0.1 \%$ SDS to remove any floating debris. Subsequent centrifugations were performed at $4000 \mathrm{~g}$ for $10 \mathrm{mins}$. The concentration of the obtained purified viral polyhedra was determined using haemocytometer.

\section{Inoculation}

In order to study the relationship between time and the larval induced mortality the purified AnprNPV were inoculated in the $3^{\text {rd }}$ instar larvae in 3 replicates (100 larvae/replication) at $3.2 \times 10^{5} \mathrm{OBs}$ (occlusion bodies) $/ \mathrm{ml}$ based on the $\mathrm{LC}_{50}$ determined from pilot experiments. The viral suspension was smeared onto the host plant Quercus serrata leaves and air dried. The $3^{\text {rd }}$ instar A. proylei larvae were allowed to feed on the virus suspension smeared leaves. The worms were then transferred to twigs inserted in bottle and reared under indoor conditions with regular feed. The mortality of the worms was then observed different days post infection and were recorded. The infectivity was tested in both spring and autumn crop to derive information of the mortality observed in these two seasons.

\section{Source of infection and surface disinfection}

In order to determine the source of infection of AnpNPV, the female A. proylei moths were collected after mating and put in separate nylon bags for egg laying for a period of 4-5 days. After oviposition, the maternal female moths were tested for the 
presence of the virus using a virus specific primer (Anpr53) in conventional PCR.

After confirmation of the infection in the female mother moths, 50 eggs were surface disinfected by immersing the eggs in $0.2 \%$ sodium hypochlorite for 20 mins after which the eggs were subsequently washed with running tap water to remove the residual disinfectant solution [5]. Another 50 eggs from the same infected mother moth were used directly without any surface disinfection and processed for further analysis. All the egg samples (both surface disinfected and non-disinfected) were washed with lysis buffer (200 mM Tris, $300 \mathrm{mM} \mathrm{NaCl}, 25 \mathrm{mM}$ EDTA with 20\% SDS). The egg washed buffer was later used for DNA isolation. Further, another 25 eggs from the infected mother moth, untreated for surface contamination, were also used for DNA isolation by crushing the eggs using mortar and pestle in order to check for the presence of the virus in the inner content of these eggs, to confirm the route of transmission of the virus. Further, 25each of treated and untreated eggs for the surface disinfection were allowed to hatch, which was later used to check for the presence of virus in these hatched larvae on the $2^{\text {nd }}$ day of hatching. The isolated DNA was used in PCR analysis using primers specific to the virus.

\section{DNA isolation from eggs and hatched larvae}

The isolation of DNA from eggs and hatched larvae was performed by crushing the samples using mortar and pestle in 200 $\mu$ l of lysis buffer (200 mM Tris, $300 \mathrm{mM} \mathrm{NaCl}, 25 \mathrm{mM}$ EDTA with $20 \%$ SDS). The crude material was mixed thoroughly and centrifuged at $3000 \mathrm{~g}$ for $5 \mathrm{~min}$ at $15^{\circ} \mathrm{C}$. The pellet and supernatant were separated and equal volume of lysis buffer was added along with $2 \mu \mathrm{l}$ of proteinase $\mathrm{K}$, followed by the incubation at $65^{\circ} \mathrm{C}$ for $1 \mathrm{hr}$. An equal volume of $\mathrm{PCl}$ (phenol chloroform Iso amyl alcohol) was added to the obtained supernatant following centrifugation at $11500 \mathrm{~g}$ for $20 \mathrm{mins}$ at $4^{\circ} \mathrm{C}$. The upper aqueous layer was transferred to another tube and an equal volume of chloroform was added, centrifuged at $11500 \mathrm{~g}$ for 20 mins. To the supernatant $50 \mu \mathrm{l} 3 \mathrm{M}$ sodium acetate and 3 volumes of chilled absolute alcohol was added and mixed by inversion. After centrifugation at $11500 \mathrm{~g}$ for 20 mins at $4^{\circ} \mathrm{C}$, the pellet was dried prior to dissolving it in $50 \mu \mathrm{l}$ of sterile nuclease free water.

\section{DNA isolation from viral particles}

To isolate viral DNA from the purified polyhedra at a concentration of $5 \times 10^{9} / \mathrm{ml}$ to $1 \times 10^{10} / \mathrm{ml}, 500 \mu \mathrm{l}$ of $0.3 \mathrm{M}$ sodium carbonate was added. This was incubated for $2 \mathrm{hrs}$ on shaker incubator followed by centrifugation at $12500 \mathrm{~g}$ for $10 \mathrm{~min}$ at $4^{\circ} \mathrm{C}$. The rest of the protocol for DNA isolation is same as described above. The obtained DNA was stored at $4^{\circ} \mathrm{C}$ for future use. The concentration of the DNA was determined using a NanoDrop 2000C (Thermo Scientific).

\section{DNA isolation from tissues}

Dissection was carried out on the diseased $A$. proylei larvae from the infected samples obtained from the sericulture fields, in order to remove tissues such as midgut, fat body, trachea, malpighian tubules and ovary for genomic DNA isolation. About $100 \mathrm{mg}$ of tissue was used for DNA isolation.

The tissue samples, such as egg, larva, pupa and moth, from different developmental stages were also collected from the sericulture fields and the DNA was isolated from $100 \mathrm{mg}$ of the tissue to check for the presence of the virus at various stages using conventional PCR analysis.

To extract the total DNA, the diseased silkworm tissues were dissected out and homogenized in lysis buffer (200mM Tris, $25 \mathrm{M}$ EDTA, $300 \mathrm{mM} \mathrm{NaCl}$ and $2 \%$ SDS) carried out by treatment with phenol: chloroform: isoamyl alcohol (25:24:1). After centrifugation the organic phase was transferred to fresh tube and chilled isopropanol was added. The insoluble DNA fibres were centrifuged at maximum speed for $5 \mathrm{~min}$ and the pellet was washed with $70 \%$ ethanol, air dried and dissolved in $30 \mu \mathrm{l}$ of sterile water. Using a UV-spectrophotometer the concentration of DNA was quantified. The quality of DNA was determined using agarose gel electrophoresis (0.8\%).

\section{Cross-infectivity of virus}


The cross-infectivity of AnpINPV was studied by inoculating $3^{\text {rd } i n s t a r ~ s i l k w o r m ~ l a r v a e ~ o f ~ S . r i c i n i, ~ A . p e r n y i, ~ A . f r i t h i ~ a n d ~ P h a l e r a ~}$ raya, Hablaea peura, Pieris canidia and P. brassicae with AnprNPV.

An AnpNNPV suspension of $3.2 \times 10^{5} \mathrm{OBs} / \mathrm{ml}$ was prepared and viral suspension was applied on leaves which were air dried before being fed. The larvae were fed with leaves smeared with the viral suspension for the first feed after starving them for $3 \mathrm{hrs}$. For subsequent feeds, fresh foliage was provided daily till pupation or death and mortality was recorded daily. The cultures were maintained appropriately by a routine cleaning on a daily basis for removing the excreta.

\section{RNA extraction and cDNA synthesis}

The RNA was extracted using Trizol (RNAiso plus, Takara) and a method previously described by Esvaran et al. (2019) [7] and it was reverse transcribed as per manufacturer's protocol (PrimeScript 1st strand cDNA synthesis kit, Takara) to generate the cDNA. The obtained cDNA was then diluted 10-fold and then used for conventional as well as quantitative Real time PCR (qRT-PCR) analysis.

\section{Conventional PCR}

A conventional PCR reaction was optimized for the diagnosis and detection of AnprNPV infection from infected larvae, tissues and developmental stages. The primer was designed based on the whole genome sequence (GenBank accession no. LC375539.1). Among the identified primers the Anpr53 gene was found to be the ideal target gene for identification of the AnprNPV and the primer sequence is presented in Table 1 [17].The PCR reaction mixture comprised of a total volume of $10 \mu \mathrm{IPCR}$ mixture composed of $1 \mu \mathrm{l}$ of genomic DNA, $0.1 \mu \mathrm{M}$ of each forward and reverse primers, $5 \mu \mathrm{l}$ of $2 \mathrm{X}$ PCR buffer, EmeraldMaster Mix (EmeraldAmp® GT PCR Master Mix, TaKaRa). The samples were subjected to the following thermal profile for amplification: 2 min at $94^{\circ} \mathrm{C}$, followed by 30 cycles of $\left[30 \mathrm{~s}\right.$ at $94^{\circ} \mathrm{C}, 30 \mathrm{~s}$ at $55^{\circ} \mathrm{C}$ and $1 \mathrm{~min}$ at $\left.72^{\circ} \mathrm{C}\right]$ in a BioRad T100 Thermal cycler. The PCR products were resolved on a $1.2 \%$ agarose gel stained with ethidium bromide for visualization of the amplified product.

\section{Real Time qPCR}

To quantify the AnpINPV virus from infected $A$. proylei samples, real time PCR was carried out in different tissues like midgut, Malpighian tubules, fatbody, trachea and ovary as well as different stages such as infected larva, pupa, moth, egg, and egg shell. Using the specific primer (Anpr53) designed for amplification of DNA with 18S as internal control, amplification was carried out. A non-template control was also used in the assay. The PCR reaction mixture comprised of a total volume of $10 \mathrm{ml}$ with $1 \mathrm{ml}$ of the diluted cDNA, $0.1 \mu \mathrm{M}$ of each forward and reverse primers, $5 \mathrm{ml}$ of SYBR Premix Ex Taq II (TliRnaseH Plus). The samples were subjected to the following thermal profile for amplification: 2 min at $94^{\circ} \mathrm{C}$, followed by 30 cycles of [30 s at $94^{\circ} \mathrm{C}, 30 \mathrm{~s}$ at $57^{\circ} \mathrm{C}$ and $1 \mathrm{~min}$ at $72{ }^{\circ} \mathrm{C}$ ]. The PCR products were resolved on a $1.2 \%$ agarose gel and stained with ethidium bromide for visualization of the amplified product. The reactions were carried out on an Agilent Technologies Stratagene Mx3005P real time PCR machine with each sample tested in triplicates and the mean values were used for determining the copy number of virus.

The unknown samples were compared against the standard curve generated by serial dilutions of the Anpr53 gene cloned into a pJET plasmid (CloneJET PCR Cloning Kit-Thermo Fisher Scientific, USA) for determination of copy numbers.

\section{Results}

\section{Disease survey}

The silkworm samples were collected during the spring and autumn seasons of 2017-2018 in Manipur and Nagaland states, India. Based on survey analysis, the disease occurrence and mortality were higher in the autumn (75.2\%) compared to the spring season(42\%) (Fig.1). The disease was identified based on the symptoms and PCR analysis using primers specific to 
the infecting NPV. Also, it was noted that the mortality was higher in the Thumkhonglok_village of the Churachandpur district in the Manipur state during both spring and autumn seasons.

Further, the correlation analysis revealed significant (at $1 \%$ and $5 \%$ of probability) positive correlation between abiotic factors on the mortality of the larvae Table 2.Larval mortality was found to increase with changes in temperature and humidity in both spring and autumn seasons, respectively.

\section{Transmission Electron Microscopy (TEM)}

The TEM images confirmed the presence of the occlusion derived virus (ODVs) of baculovirus in the infected tissue samples from A. proylei silkworms. The image displays the presence of occlusion bodies enclosed within a common envelope (Fig.2).

\section{Infectivity of virus}

The infectivity of the virus was tested by inoculating disease-free $3^{\text {rd }}$ instar larvae with AnprNPV virus isolated from diseased silkworms. Based on the viral inoculum dosage, the number of days of survival and gradual progression to death of the larvae was recorded. For the spring crop, the larval mortality post infection was observed to start from day 6 which gradually increased to reach $100 \%$ mortality on day 13 . However, for the summer crop (autumn) the mortality began at the $5^{\text {th }}$ day post infection gradually increasing to reach $100 \%$ mortality on the $10^{\text {th }}$ day (Fig.-3). The data indicate that the larvae reached mortality faster in the autumn months when the temperature and humidity peaks.

\section{Source of infection, surface disinfection and vertical transmission}

The DNA collected from the eggs laid by female-infected moth was subjected to PCR analysis and confirmed the presence of the virus in eggs. The result also supports the absence of the virus particles in the inner content of the egg after performing surface disinfection. From these experiments it can be concluded that the source of infection of the virus to be the surface of the contaminated eggs laid by the infected A. proylei female moths (Fig. 4).

Surface disinfection is a commonly used method to remove surface contaminants in the sericulture field, which ensures that the newly hatched larvae are free from infection. Hence, in this study a $0.2 \%$ sodium hypochlorite disinfection treatment is devised for the eggs laid by the AnprNPV-infected mother moth. The DNA from the disinfected eggs, when checked through conventional PCR, did not show any presence of the AnpINPV (Fig. 4). Hence, the surface disinfection with $0.2 \%$ sodium hypochlorite solution was found to be effective in removing the viral particles from the surface-contaminated eggs.

The DNA isolated from the surface-treated and untreated eggs were used in PCR amplification with the virus specific primers (Anpr53).The surface-disinfected egg samples showed amplification bands with virus specific primer, whereas the nondisinfected egg samples showed no bands. The inner contents from the surface-treated egg samples also did not display presence of any virus indicating the transmission route of the virus to be transovum in nature. The hatched larvae from the non-disinfected sample also displayed the presence of virus. This might be attributed to the presence of virus on the surface, which may have been ingested by the larvae during eclosion (Fig. 4).

\section{Tissue tropism}

When the tissue samples from the infected $A$. proylei larvae were tested, viral particles were observed in tissues such as midgut, fat body, trachea, Malpighian tubules and ovary. The presence of virus was also noted in various development stages of silkworm A. proylei, as amplification bands were observed in the conventional PCR analysis of pupa, moth and egg samples (Fig. 5A). The viral copy number in each of these tissues and developmental stages were quantified using qPCR (Fig. 5B \& C), which showed presence of the virus and a higher copy number in the fat body indicating the virus preference for this tissue.

\section{Cross-infection of AnpNPV}


Phalera raya, Hyblaea peura, Pieriscanidia and Pieris brassicae were able to develop into adult stage even after infection with AnpNNPV. However, S. ricini, A. pernyi, and A. frithidied acquiring the infection, hence indicating their susceptibility to the AnprNPV infections (Fig.6). The study confirmed that the AnprNPV can infect other lepidopterans in the Saturniidae family, specifically the silkworm species used in this study.

\section{Discussion}

Antheraea proylei is the most prominent, viable and commercially exploited species in India and is one of the economically important silkworms. Since A. proylei is reared outdoors, they are frequently infested with different pathogens, one of them being A. proylei NPV causing tigerband disease in these silkworms [18]. Based on the study performed by Shantibala et al. (2018) the causative agent for the tiger band disease has been confirmed as a group 1 alphabaculovirus. In the present study an attempt has been made to understand the source of infection and pathogenesis of the tiger band disease.

Since the discovery of AnprNPV virus, its mode of infection is not very well understood. In the current study the infectivity of the virus till larval mortality was monitored by inoculating the virus into young larvae to observe the progression of the disease towards larval mortality. A 100\% mortality was observed in both crop seasons viz., spring and autumn. However, the disease progression was faster in the autumn season as compared to the spring season indicating acceleration of the disease-induced mortality during this season.

Transmission electron micrograph showed single rod-shaped occlusion derived virus (ODV) embedded in a granular OB. These are typical granulovirus morphological characteristics. From TEM cross sections, AnprNPV OBs spanned approximately $1.16 \mu \mathrm{m} \times 1.06 \mu \mathrm{m}$, which falls within the range of dimensions reported for alphabaculovirus OBs [9]. This is the first report of TEM image of OBs observed in infected Antheraea proylei silkworm.

During the disease survey in spring and autumn months in various districts of Manipur state, a direct positive correlation was noted between the larval mortality and the abiotic factors such as temperature and humidity, which has been found to be higher during these seasons. However, the mortality was higher in the autumn crop due to adverse climatic conditions and poor feed quality.

To check for tissue tropism, the silkworm tissue samples from midgut, fat body, epidermis, ovaries, testis, head and haemocyte were dissected and the DNA was checked for the presence of virus using qRT-PCR to quantify the viral load the Anpr53(he65-like) gene segment was selected for the detection of AnpINPV as it had consistent amplification and also has been indicated previously as the gene specific to the NPV [18]. Results revealed higher copy numbers of AnprNPV in the fat body tissue of tiger-band diseased silkworms. In comparison, relatively lower copy numbers of the AnprNPV were noted in other diseased tissues (midgut, Malpighian tubules, trachea and ovary). Katsuma et al., [11] also support this finding, where a poor replication has been reported in silk glands, midgut, and Malpighian tubules tissues of Bombyx mori NPV infected larvae. However, the molecular mechanism involving tissue tropism of baculovirus is largely unknown and may vary [11]. The AnprNPV was found to be present in all the developmental stages of the silkworm indicating its ability to thrive throughout all these stages.

It has long been known that many invertebrate pathogens can be transferred directly from infected hosts to their offspring [20]. A review by Kukan [12] indicates that the disease is transmitted from parents to offspring reared from surfacedecontaminated eggs and later observed in developing caterpillars. The study also indicated that the source of contamination is probably through the environmen. Hence, to test this hypothesis in the current study, the eggs laid by the infected mother moth were checked for the presence of the AnprNPV. The surface disinfection was employed to compare the treated vs. untreated eggs in order to understand the source on the contamination as well as the route of transmission. The infecting virus was found to be present on the surface of the eggs whereas it was absent in the inner egg contents, hence indicating that the virus follows the transovum transmission route. This can be attributed to the newly hatched larvae feeding on pieces of egg shell "chorion" to survive until capable of feeding on the host plants, hence ingesting any 
accompanying pathogen thriving on the egg surfaces [14]. Thus, understanding on the vertical transmission will further help to undertake appropriate controls at the egg production stage.

The AnprNPV is a regional variant of the AnpeNPV and it is expected that this virus could cause disease mortality also in $A$. pernyi. An earlier report on cross-infectivity of AnpeNPV, showed that it caused 57\% mortality in larvae of Samia cynthia ricini, whereas PCrNPV did not kill the larvae of $A$. pernyi [16]. To test this hypothesis, a cross-infectivity experiment of $A n p r N P V$ on the Saturniid silkworms A. pernyi, A. frithi and S. ricini as well as the lepidopteran pests Phalera raya, Hablaea peura, Pieris canidia and Pieris brassicae were conducted and indicated a greater susceptibility of the silkworm clade, which died acquiring the infection. This suggests that AnprNPV is specific for the Saturniid family.

Disinfection is a common action to prevent surface contamination of newly hatched larvae [10] and surface decontamination of eggs may reduce the disease occurrence by over 10-fold in several insect viral pathogens [20]. Greis and Petkov [8] in their studies have shown that disinfection of Bombyx mori eggs with surface disinfection using $2 \%$ formalin resulted in increased silkworm viability (1.60-4.49\%) and raw cocoon yield by $0.50-2.10 \mathrm{~kg}(2.11-7.83 \%)$. In conventional method $0.5 \% \mathrm{NaOH}$ with $3 \%$ formalin is being used to surface disinfect the $A$. proylei eggs to remove the virus which was not only ineffective but also had adverse effect on hatching ability of these eggs. As an alternative, a new surface disinfection technique was devised using $0.2 \%$ sodium hypochlorite, which was found to be highly effective in removing the virus contamination from the surface of the infected eggs. This was also corroborated successfully by the source of infection experimentation which was used for testing the effective virus removal where the surface disinfection of the surface contaminated eggs was successfully removed, yielding healthy larvae. The disinfection technique is highly beneficial and can be employed at egg production centres in order to supply disease free eggs to the sericulture farmers.

The study provides substantial details on the disease prevalence, infectivity, source, mode of infection, tissue tropism and vertical transmission of the AnprNPV virus. The study also provides control measures such as a surface disinfection technique for the eggs which will help prevent the spread of the disease. Cross-infectivity experiments confirmed that the virus can be highly virulent for other silkworms. A PCR technique and a qRT-PCR technique developed from this study can be utilised to screen the field samples for early identification of the pathogen. However, more information on the virus may be required and hence need further research in order to understand the host pathogen interactions, the immune response to the infection and also development of a field based diagnostic kit.

\section{Declarations}

\section{Acknowledgement}

The authors thank Central Silk Board, Govt. of India for providing the financial support and infrastructure facilities to carry out research.

\section{Funding}

The authors thank DBT (Department of Biotechnology), India (Grant No.: BT/PR15405/TDS/121/14/2015 dt 09.02.2017) and the Swedish Research Council (Grant No: 2017-05463) for their support and financial assistance throughout this study.

\section{Author contribution}

DK: designed, executed the study, wrote the manuscript; SS: designed, executed the study, technical inputs; AJ: Editing and technical inputs; HD editing the manuscript, provided technical advice and scientific inputs; JK: Technical advice and scientific inputs, VS: technical support and infrastructural support; KMP: Designed the study framework, technical advice and scientific inputs; all authors have edited the paper. All author(s) have read and approved the final manuscript.

\section{Conflict of interest}


The authors declare no conflict of interest

\section{Data availability}

Data will be made available upon reasonable request to the senior author Dr. K. M. Ponnuvel.

\section{References}

1. Aragão-Silva CW et al (2016) The complete genome of a baculovirus isolated from an insect of medical interest: Lonomia obliqua (Lepidoptera: Saturniidae). Sci Rep 6:23127. https://doi.org/10.1038/srep23127

2. Balagopalan U et al., 2009. Indigenous knowledge of silkworm cultivation and its utilization in North Eastern region of India. Indian J. Tradit. Knowl. 70-74

3. Bergren NA, Kading RC (2018) The ecological significance and implications of transovarial transmission among the vector-borne bunyaviruses: A Review. Insects 9. https://doi.org/10.3390/insects9040173

4. Bukhari R et al., 2019. Non: Mulberry Sericulture. J. Pharmacogn. Phytochem. 311-323

5. Devi S et al., (2019). Sodium hypochlorite disinfection- An effective disinfection for silkworm eggs to protect against tiger band disease. Brochure published by the RTRS, Imphal (Central Silk Baord, Government of India)

6. Elumalai D (2021) Introduction to Non-Mulberry Silkworms. CRC Press, pp 24-25

7. Esvaran VG et al (2019) Development and comparison of real-time and conventional PCR tools targeting $\beta$-tubulin gene for detection of Nosema infection in silkworms. J Parasit Dis 43:31-38. https://doi.org/10.1007/s12639-018-1053-4

8. Greis H, Petkov N (2000) Study on disinfection of silkworm seeds (Bombyx mori, L.). Zhivotnovdni Nauki 37:68-71

9. Herniou EA, Arif BM, Becnel JJ, Blissard GW, Bonning B, Harrison RL et al. Baculoviridae In: King AMQ, Adams MJ, Carstens EB, Lefkowitz EJ (eds) Virus Taxonomy: Ninth Report of the International Committee on Taxonomy of Viruses. Oxford: Elsevier; 2012. pp 163-174

10. Hukuhara T (2018) The epizootiology of pebrine, one of the great scourges of sericulture. J Biochem Biotechnol 01. https://doi.org/10.35841/biochemistry-biotechnology.1.1.1-3

11. Katsuma S et al (2012) Baculovirus-Encoded Protein BV/ODV-E26 determines tissue tropism and virulence in lepidopteran insects. J Virol 86:2545-2555. https://doi.org/10.1128/JVI.06308-11

12. Kukan B (1999) Vertical transmission of nucleopolyhedrovirus in insects. J. Invertebr. Pathol. 103-111

13. Mansotra DK, Joshi PC (2020) Biochemical changes in the haemolymph, silk gland and fat body of the tiger band infected larvae of oak tasar silkworm, Antheraea proylei Jolly.Current Status of Researches in Biosciences. 23-31

14. Miya K (1984) Early Embryogenesis of Bombyx mori. In: King RC, Akai H (eds) Insect Ultrastructure. Springer, Boston. https://doi.org/10.1007/978-1-4613-2715-8_2

15. Nagaraju J, Jolly MS (1986) Interspecific hybrids of Antheraea roylei and A. pernyi - a cytogenetic reassessment. Theor Appl Genet 72:269-273. https://doi.org/10.1007/BF00267003

16. Qian H et al (2013) Analysis of the genomic sequence of Philosamia Cynthia nucleopolyhedrin virus and comparison with Antheraea pernyi nucleopolyhedrin virus. BMC Genomics 14:115. doi:10.1186/1471-2164-14-115

17. Reid S, Chan L, van Oers MM (2014) Chapter 13 -Production of Entomopathogenic Viruses. In: Morales-Ramos JA, Rojas MG, Shapiro-llan DI (eds) Mass Production of Beneficial Organisms. Academic Press, San Diego, pp 437-482. https://doi.org/10.1016/B978-0-12-391453-8.00013-3

18. Shantibala T et al., 2018. Genetic characterization of an alphabaculovirus causing tiger band disease in the oak tasar silkworm, Antheraea proyleiJ (lepidoptera: Saturniidae). Sericologia58, 91-111

19. Trelease W (1924) The American oaks. Govt. Print. Off, Washington:https://doi.org/10.5962/bhl.title.142965

20. Williams, T., et al., 2017. Covert Infection of Insects by Baculoviruses. Front. Microbiol. 8, 1337.

https://doi.org/10.3389/fmicb.2017.01337

Page 9/15 


\section{Tables}

Table 1: Primers used in this study

\begin{tabular}{|lll|}
\hline SI No. & Primer name & Sequence $\left(\mathbf{5}^{\prime} \mathbf{3}^{\prime} \mathbf{)}\right.$ \\
\hline 1. & Anpr53 qPCR F & GCAGCAATTTCCTTCCAAAG \\
\cline { 2 - 3 } & Anpr53 qPCR R & TCTGTTGACGCTCTTGTTGG \\
\hline 2. & Anpr53 F & TCTGTTGACGCTCTTGTTGG \\
\cline { 2 - 3 } & Anpr53 R & TGTGGTACGTTGCCGAGATA \\
\hline 3. & 18SF & ATGACGGAAGGGCACCACCAG \\
& 18SR & GCACCACCACCCACGGAATCG \\
\hline
\end{tabular}

Table 2.Correlation between temperature, humidity with larval mortality during spring and autumn crops

Details Correlation ( $r)$

\begin{tabular}{|c|c|c|c|c|c|c|c|c|c|c|}
\hline & \multicolumn{2}{|c|}{ RTRS, Imphal } & \multicolumn{2}{|c|}{ REC, Yaikangpao } & \multicolumn{2}{|c|}{ REC, Kikruma } & \multicolumn{2}{|c|}{ Thumkhonglok } & \multicolumn{2}{|c|}{ Dolansabi } \\
\hline & Spring & Autumn & Spring & Autumn & Spring & Autumn & Spring & Autumn & Spring & Autumn \\
\hline $\begin{array}{l}\text { Larval } \\
\text { mortality vs } \\
\max \\
\text { temperature }\end{array}$ & $0.68^{* *}$ & $0.56^{\star}$ & $0.59 *$ & $0.51 *$ & $0.68 * \star$ & 0.35 & $0.55^{\star}$ & $0.79 * \star$ & $0.50 *$ & $0.52^{\star}$ \\
\hline $\begin{array}{l}\text { Larval } \\
\text { mortality vs } \\
\text { min } \\
\text { temperature }\end{array}$ & 0.24 & 0.34 & $0.51^{*}$ & 0.21 & $0.57 *$ & 0.48 & $0.58 *$ & 0.35 & $0.51 *$ & 0.21 \\
\hline $\begin{array}{l}\text { Larval } \\
\text { mortality vs } \\
\text { R.H }\end{array}$ & $0.78^{* *}$ & $0.54^{*}$ & $0.80 * *$ & $0.61^{* *}$ & $0.80 * *$ & $0.54^{\star}$ & $0.78^{* *}$ & $0.55^{\star}$ & $0.80 * *$ & 0.61 ** \\
\hline $\begin{array}{l}\text { Larval } \\
\text { mortality vs } \\
\text { Rainfall }\end{array}$ & 0.45 & 0.22 & $0.66^{\star \star}$ & $0.53^{*}$ & 0.4 & $0.83^{\star *}$ & $0.63^{*}$ & 0.49 & $0.62^{\star \star}$ & 0.04 \\
\hline
\end{tabular}

*Significant at $5 \%$ level of probability; **Significant at $1 \%$ level of probability

\section{Figures}




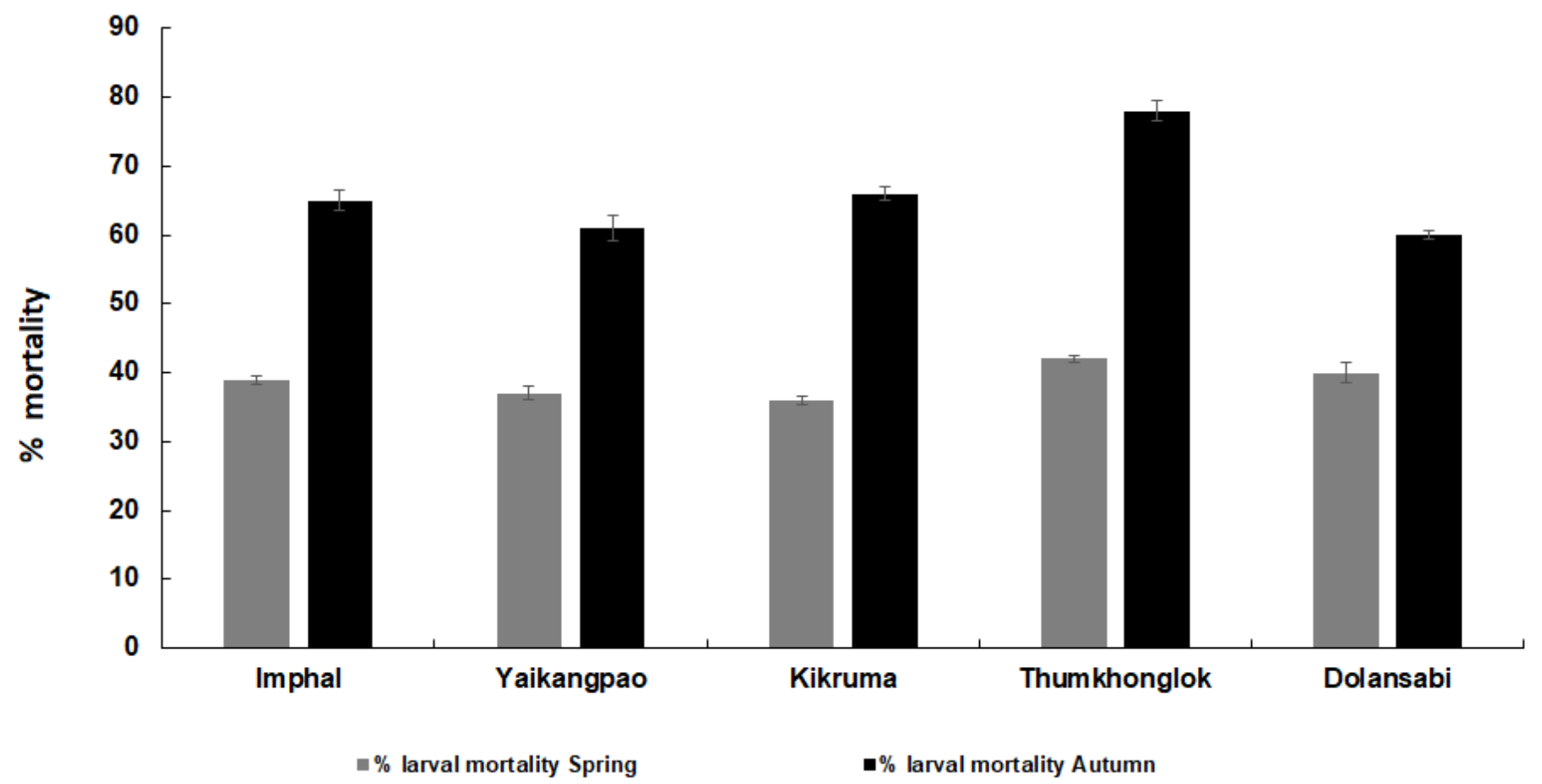

\section{Figure 1}

Survey analysis of the tiger band disease prevalence in north eastern regions of India. The graph depicts the percentage mortality in the spring and autumn season in:Imphal, Yaikangpao, Kikruma, Thumkhonglok, Dolansabi.

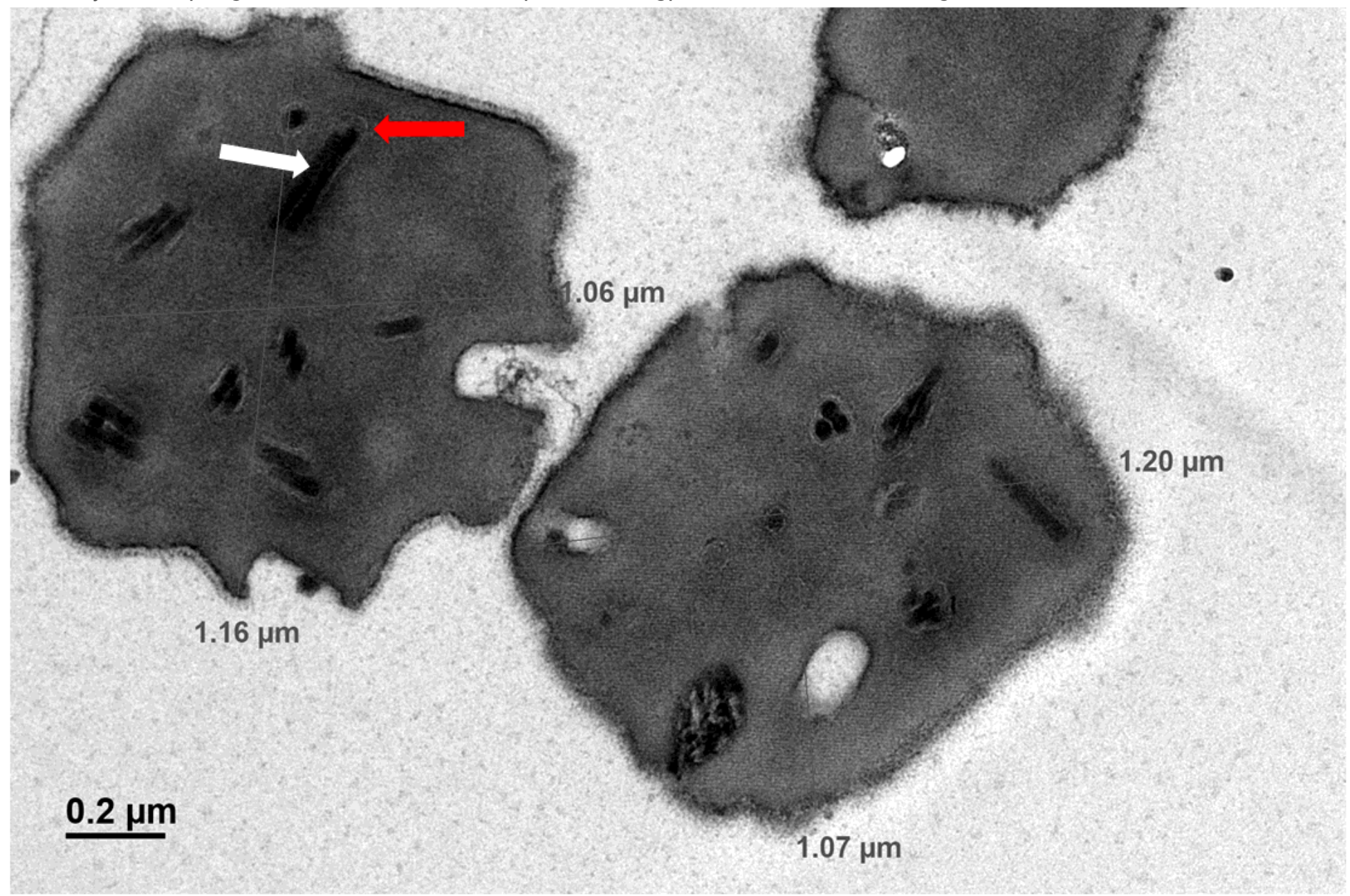




\section{Figure 2}

TEM images of purified AnprNPV OBs. Transmission electron micrographs of AnprNPV OBs. The arrow denotes the envelope surrounding the rod-shaped nucleocapsid of a virion. The nucleocapsid (white arrow) and surrounding envelope (red arrow) of an occluded virion are indicated in the above image.[TEM was performed at the Electron Microscopy - Common Research Facility, Department of Neuropathology, National Institute of Mental Health \& Neurosciences, Bangalore, India.]

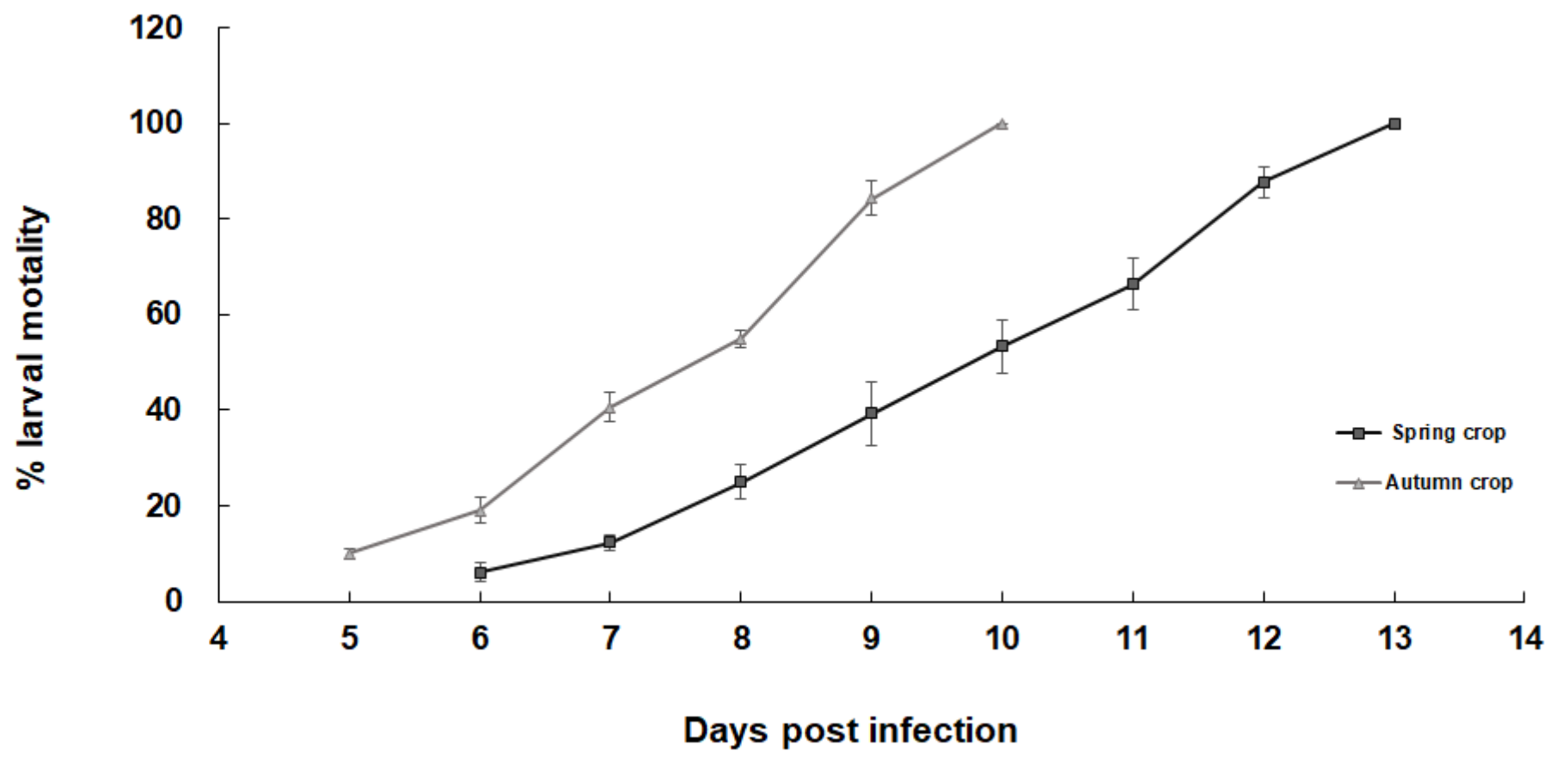

\section{Figure 3}

Infectivity of the AnprNPV on 3rd instar A. proylei larvae indicating percentage larval mortality in spring and autumn seasons. Error bars indicate the standard deviation of 3 replicates. 


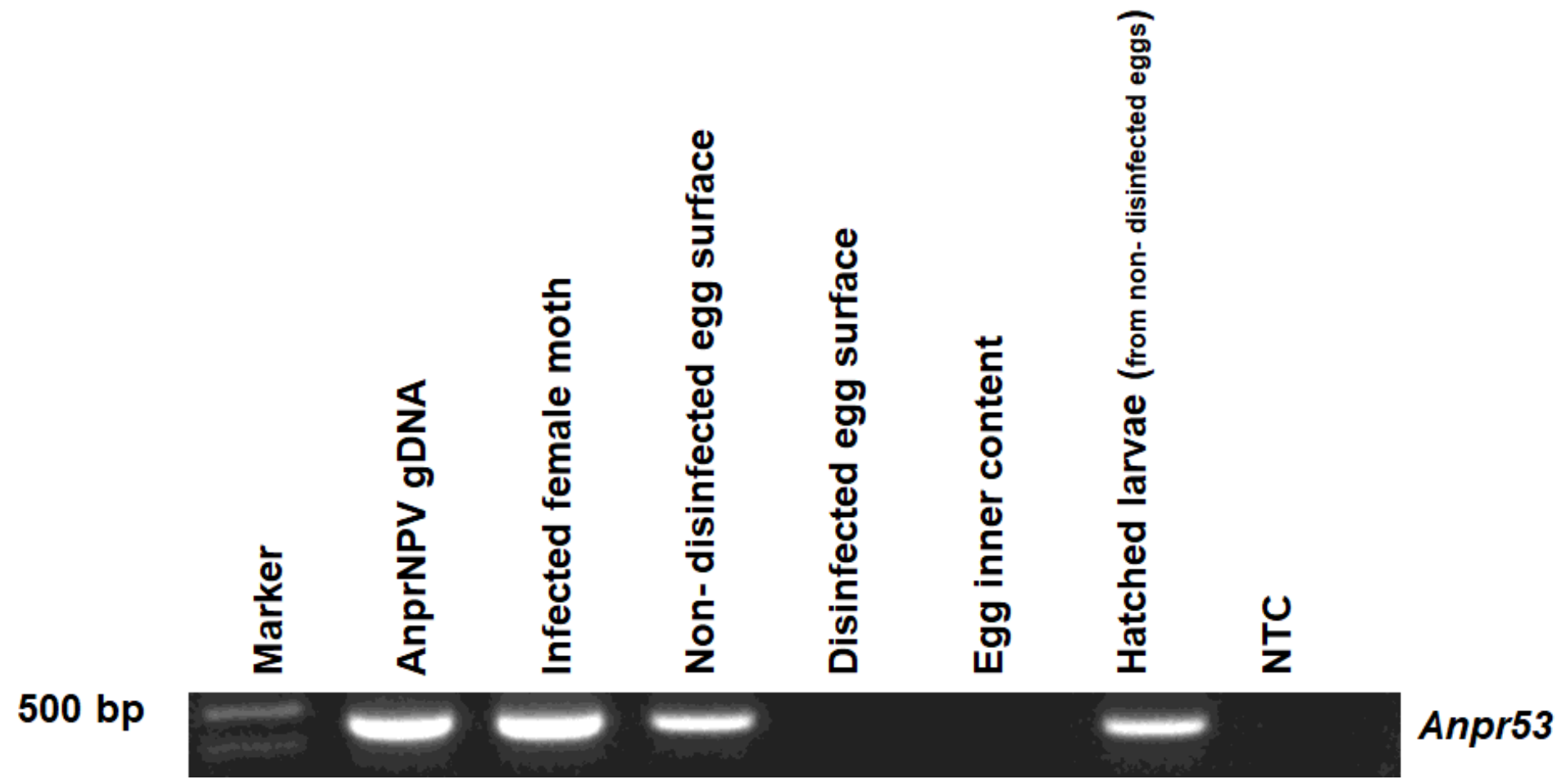

Figure 4

Source of infection tested on the eggs laid by the NPV infected A. proylei female moth. The PCR analysis of the egg surface before and after surface disinfection, eggs inner contents and the hatched larvae from the untreated eggs. The analysis was performed using Anpr53 for NPV detection, $18 \mathrm{~S}$ as internal control along with AnprgDNA as positive control and a NonTemplate Control (NTC) in the analysis. 


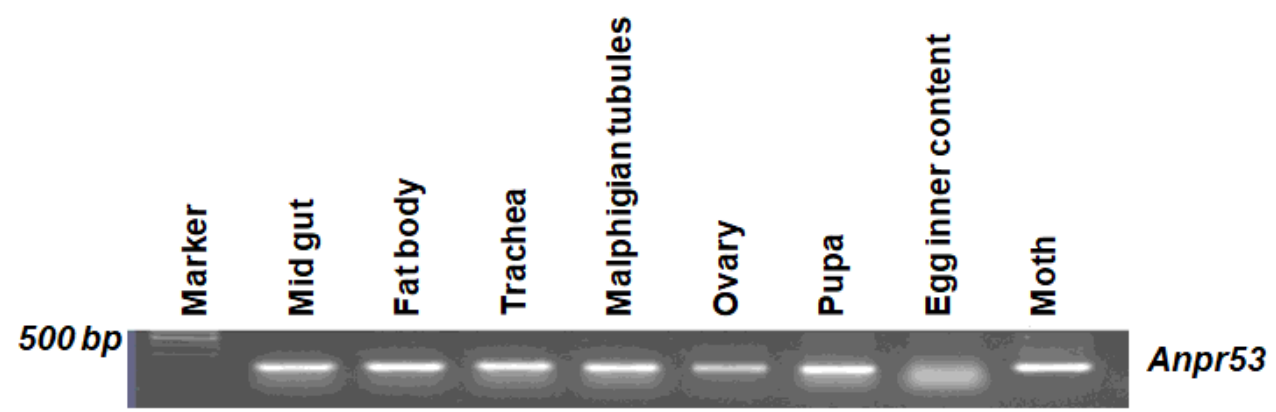

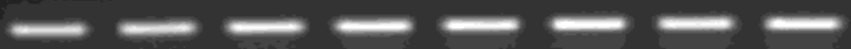

$18 S$

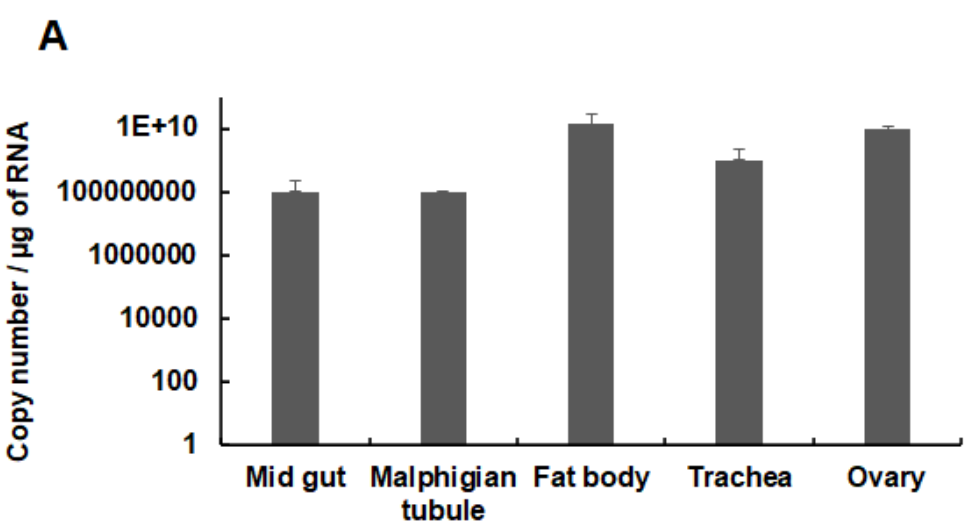

B

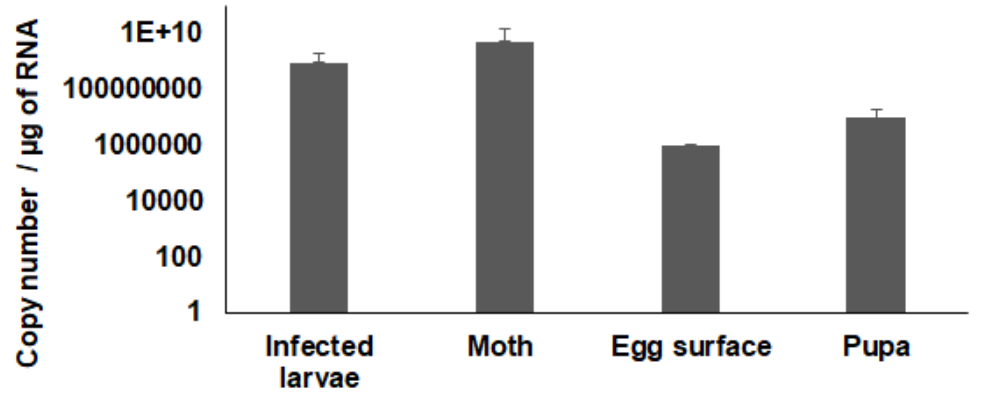

\section{Figure 5}

Conventional PCR analysis of different tissues such as midgut, fat body, trachea, Malpighian tubules and ovary dissected out of the NPV infected field A. proyleilarval samples. Anpr53 was used to detect the presence of NPV and 18S is used as internal control along with viral DNA / Anpr gDNA at positive control. NTC without the DNA template has also been used in the analysis. B \& C: qPCR analysis displaying the NPV load in the infected tissue samples as well as samples from different development stages (larva, egg, pupa and moth). The error bars indicate the standard deviation of 3 replicates. 


\section{Image not available with this version}

\section{Figure 6}

Transmission route of the virus displayed through the surface disinfection treatment of the eggs contaminated with virus on its surface.

\section{Image not available with this version}

Figure 7

Cross-infectivity of AnprNPV to other silkworms such as A. frithi, A. pernyiand S. Ricini and also on other lepidopteran pests such as P. raya, H. peura, P. canidia and P. brassicae using Anpr53 primer, 18 S internal control and NTC. 